\title{
Volume loss of the Greenland ice sheet revealed by SARAL/AltiKa repeat passes radar altimetry
}

\author{
Maya Raghunath Suryawanshi ${ }^{1,2, *}$, Shard Chander $^{1}$, Sandip R Oza $^{1}$ and I M Bahuguna ${ }^{1}$ \\ ${ }^{1}$ Space Applications Centre (ISRO), Ahmedabad, India. \\ ${ }^{2}$ Department of Physics, Electronics and Space Science, Gujarat University, Ahmedabad, India. \\ ${ }^{*}$ Corresponding author. e-mail: maya2509.surya@gmail.com
}

MS received 28 August 2018; revised 7 February 2019; accepted 16 April 2019; published online 5 July 2019

The Greenland ice sheet (GrIS) is one of the drivers of global sea level rise and plays a crucial role in understanding the global climate changes. Here, we have estimated and analysed the decadal (between 2013-2016 and 2003-2005) and annual (2014-2015, 2015-2016) volume discharge of ice from the entire GrIS. The $40 \mathrm{~Hz}$ Geophysical Data Record product of the unique Ka band (AltiKa) radar altimeter were utilised to derive the elevation, elevation changes and volume changes over the GrIS. To test the firstlevel accuracy of the result, AltiKa and NASA's ice, cloud and land elevation satellite digital elevation model (ICESat DEM)-derived elevation were compared, which yielded a correlation value of 0.95. Thereafter, decadal volume changes obtained over the entire GrIS, from the differencing of the AltiKa and ICESat DEM elevation revealed a decreasing rate of $247 \mathrm{~km}^{3}$ /year. Moreover, basin-wise analysis indicated the maximum decrease in elevation of basin located in the north and north-west region of GrIS. Annual changes obtained by differencing the AltiKa cycle of the same month (so that the surface condition will remain same) between the two consecutive years, specifically during 2014-2015 and 2015-2016 over the entire GrIS contributed volume loss of 187 and $210 \mathrm{~km}^{3}$, respectively, indicating an enhanced decrease for a later period.

Keywords. Greenland ice sheet; elevation change; volume change; SARAL/AltiKa; radar altimeter.

\section{Introduction}

The Greenland ice sheet (GrIS) and its response to global climate changes are one of the major concerns to scientific community. Indeed, GrIS is the largest exclusive source of sea-level rise and will remain so for decades as per the Fifth Assessment Report of the Intergovernmental Panel on Climate Change (Van den Broeke et al. 2017). This invokes an urgent need for its change estimation. The GrIS being remote, vast and hostile, remote sensing has played a key role in observing and predicting the changes occurring over it. Three main approaches utilised to assess the polar ice sheet changes are the input-output method, gravimetry and altimetry. First, one is a ground-based method while the other two are remote sensing-based methods. Recently, Wang et al. (2018) used gravity recovery and climate experiment gravity field and surface mass balance data (RACMO2.3) of duration 2003-2015 to study GrIS. The third approach is altimetry, so far various laser and radar altimeters were widely utilised in mapping the topography (DiMarzio et al. 2007; Helm et al. 2014) and estimating the discharge of GrIS (Krabill et al. 2004; Li and Davis 2008; Helm et al. 2014). All of these studies show a high thinning rate, near the coastal region and stable or slight thickening at the interior of the 
GrIS. Furthermore, the thinning rate was measured to be higher below $2000 \mathrm{~m}$ elevation, as compared to the elevation above $2000 \mathrm{~m}$ (Krabill et al. 2000). A drastic thinning rate was observed over the fastest moving Jakobshavn glacier, located near the coast in the south-western region of the GrIS (Rignot and Kanagaratnam 2006). Thereby, it adds high amount of ice mass discharge into the ocean and acting as a potential driver to sea-level rise.

However, altimeter data require retracking and slope correction to use it for ice-sheet studies (Bamber 1994). Due to surface irregularities, tracking gate fails to track the midpoint of the leading edge, which leads to an incorrect measurement of the range of the satellite and henceforth incorrect elevation measurement. Therefore, 'retracking' is required to track the midpoint of the leading edge accurately (Bindschadler et al. 1989). Secondly, the slope of the terrain displaces the range measurement from the original nadir point introducing the 'slope induced error' of a few kilometres for a satellite at an altitude of $800 \mathrm{~km}$ (Hurkmans et al. 2012). To mitigate the effect of this error, slope correction is required.

Apart from the above-mentioned error, high correlation observed between backscatter change and elevation change over some regions of interest (ROI) of the Antarctic ice sheet led to an error in the measurement of elevation changes (Davis and Ferguson 2004; Qiang et al. 2015). However, Brenner et al. (2000) concluded that corrections to $\mathrm{d} h / \mathrm{d} t$ for variations in backscatter are not appropriate, at least for Greenland.

Most of the altimeter-based studies mentioned above were carried out using either $\mathrm{Ku}$ band radar altimeters or laser altimeters while very few studies (over GrIS) have been reported with Ka band (Chander et al. 2015; Yang et al. 2018). Ka band frequency being higher than $\mathrm{Ku}$ penetrates less into the surface giving rise to near subsurface volume echo and reduces ionosphere correction to be applied to the height measurement. Sharp antenna aperture will give a stable height measurement over time and a higher pulse repetition frequency gives along the track spacing of $175 \mathrm{~m}$ for a $40 \mathrm{~Hz}$ dataset better than $370 \mathrm{~m}$ as in the case of the $20 \mathrm{~Hz}$ dataset of an earlier altimeter mission like Envisat (Remy et al. 2014).

At present, SARAL/AltiKa (launched on 25 February 2013) is the only altimeter with Ka $(35.75 \mathrm{GHz})$ band frequency. In the present study, we have utilised SARAL/AltiKa Exact Repeat Mission (ERM) dataset and NASA's Ice, Cloud and land Elevation Satellite Digital Elevation Model (ICESat DEM) dataset to quantify decadal and annual elevation and volume changes occurring over the GrIS. Along with the Airborne Topographic Mapper (ATM) dataset (https:// nsidc.org/icebridge/portal/map) was also utilised for the validation of AltiKa-derived elevation changes, which is described in section 3.1.

\section{Data and methodology}

We have utilised $40 \mathrm{~Hz}$ Geophysical Data Record (GDR) of SARAL/AltiKa dataset (ftp://avisoftp. cnes.fr/AVISO/pub/saral/gdr_t) of the ERM phase. ICESat DEM (DiMarzio et al. 2007) of resolution $1000 \mathrm{~m}$ was used, to incorporate slope (less than or equal to $1^{\circ}$ ) correction in elevation measurements of SARAL/AltiKa. DiMarzio et al. (2007) validated the ICESat DEM dataset with ATM data over Greenland and it has been observed that the mean difference varies with slope: for regions with less than $0.1^{\circ}$ slopes, the mean difference is $-32 \pm 43 \mathrm{~cm}$; for regions with $0.1-1.0^{\circ}$ slopes, the mean difference is $-66 \pm 61 \mathrm{~cm}$. Details of the dataset used for the entire study are mentioned in table 1.

\subsection{Method for deriving the elevation}

The $40 \mathrm{~Hz}$ GDR range and altitude measurements of the SARAL/AltiKa dataset were used to derive elevation (w.r.t. WGS84) over the GrIS. The range parameter was derived from the two-way travel of the transmitted microwave pulse. Atmospheric interaction and tide effect increases the time delay, thereby lengthening the range than the actual value. Hence, the range was corrected for various atmospheric and tidal delays:

$$
\begin{aligned}
\text { Elevation }= & \mathrm{ALT}-\text { range }-\mathrm{DTC}-\mathrm{WTC}-\mathrm{IC} \\
& -\mathrm{SETC}-\mathrm{PTC},
\end{aligned}
$$

where ALT is the altitude, DTC is the dry troposphere correction, WTC is the wet troposphere correction, IC is the ionosphere correction, SETC is the solid earth tide correction and PTC is the pole tide correction.

We have used an Ice-2 retracker-derived range in the present study as Ice-2 retracker is considered 
Table 1. Summary of the dataset used in the present study.

\begin{tabular}{lcccc}
\hline Dataset & Phase of the mission & Cycle & Start date & End date \\
\hline SARAL/AltiKa $40 \mathrm{~Hz}$ GDR dataset & ERM & 01 & 14 March 2013 & 18 April 2013 \\
& & 11 & 27 February 2014 & 03 April 2014 \\
& & 12 & 03 April 2014 & 08 May 2014 \\
& & 22 & 19 March 2015 & 23 April 2015 \\
& & 23 & 23 April 2015 & 28 May 2015 \\
& & 32 & 03 March 2016 & 07 April 2016 \\
ICESat DEM dataset & - & - & 14-35 March 2013 & 04 July 2016 \\
\hline
\end{tabular}

appropriate for the ice sheet study (Legresy et al. 2005; Remy et al. 2014; Chander et al. 2015).

Later on, these elevations were corrected for the slope-induced error, using the direct method (Brenner et al. 1983). This correction is proportional to the square of the slope value and the altitude of the satellite. A detail regarding the slope correction is mentioned in Suryawanshi et al. (2019). These slope uncorrected and corrected elevation datasets were compared with ICESat's DEM-derived elevation to check the first level accuracy of the dataset.

After slope correction, the elevation map for individual cycles (mentioned in table 1) and the average elevation map (here onwards referred to as the AltiKa35 elevation map) obtained using all 35 repeat cycles (duration: 14 March 2013-4 July 2016) of SARAL/AltiKa were generated for further analysis. AltiKa being a radar altimeter will penetrate deeper into the surface in comparison with ICESat, which is a laser altimeter. Hence, before generating the elevation difference between them, it becomes mandatory to apply correction due to penetration in the AltiKa35 elevation. To measure this bias, the AltiKa elevation derived from cycle 12 (April-May 2014) was interpolated at ATM measured elevations of 05 April 2014 over a part of GrIS and bias was calculated. Indeed, we should compare the ICESat and AltiKa datasets of the same location and same time to determine bias due to the Ka band. However, different operational time periods of these two satellites prohibited this comparison. Hence, a comparison between ATM and AltiKa was carried out, as ATM is also a laser altimeter and has a spatial and temporal overlap with the AltiKa dataset.

Furthermore, ROI- $1\left(76-77^{\circ} \mathrm{N}\right.$ and $\left.34-35^{\circ} \mathrm{W}\right)$ and ROI-2 $\left(69-70^{\circ} \mathrm{N}\right.$ and $\left.47-49^{\circ} \mathrm{W}\right)$ with average slope values of $0.19^{\circ}$ and $0.60^{\circ}$ were selected for the validation of our elevation change results. ATM dataset measured elevation change between April-May 2014 and April-May 2015 was compared with AltiKaderived slope corrected and outliers removed gridded elevation difference of cycle 23 (April-May 2015) and cycle 12 (April-May 2014).

\subsection{Elevation and volume change}

For the measurement and understanding of decadal (between 2013-2016 and 2003-2005) elevation and volume change over GrIS, the difference map of AltiKa35 (March 2013-July 2016) and ICESat DEM (February 2003-June 2005)-derived elevation was generated. Furthermore, annual elevation changes were derived by differencing AltiKa cycles of the same month (so that surface condition will remain the same) between two consecutive years. Thereafter, elevation change map of cycle 11 (February-April 2014)-cycle 01 (March-April 2013), cycle 22 (March-April 2015)-cycle 11 (February-April 2014) and cycle 32 (March-April 2016)-cycle 22 (March-April 2015) were generated. Furthermore, outliers were removed using the inter-quartile range criterion. For obtaining the volume changes, the entire GrIS was divided into 19 basins, with basin Id ranging between 1.1 and 8.2 and is marked in figure 1. After multiplying elevation changes with the individual area of the basin, the results of volume change of the given basin was obtained.

\section{Results and discussion}

\subsection{Validation of elevation and elevation changes of GrIS}

The slope corrected elevation map derived over the GrIS using the SARAL/AltiKa dataset of cycle 01 (14 March-18 April 2013) is displayed in figure 2. 


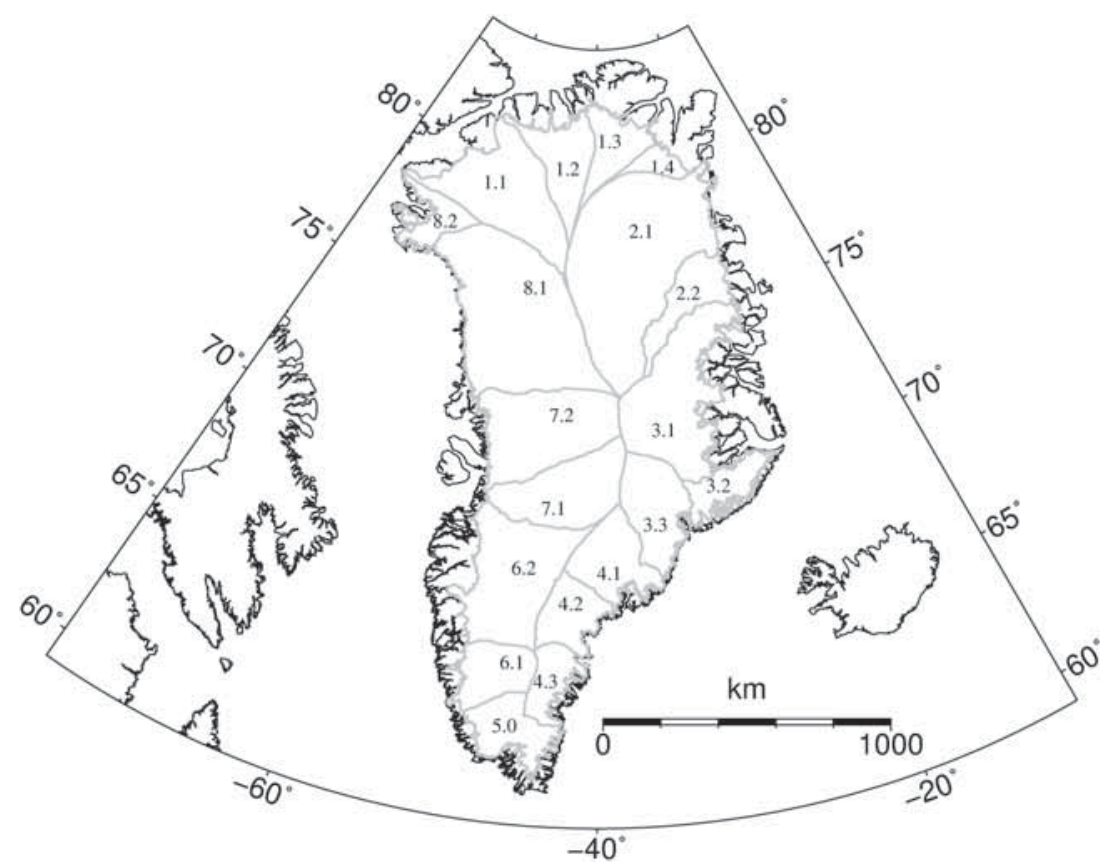

Figure 1. Drainage basin system of GrIS was adapted from Zwally et al. (2012).
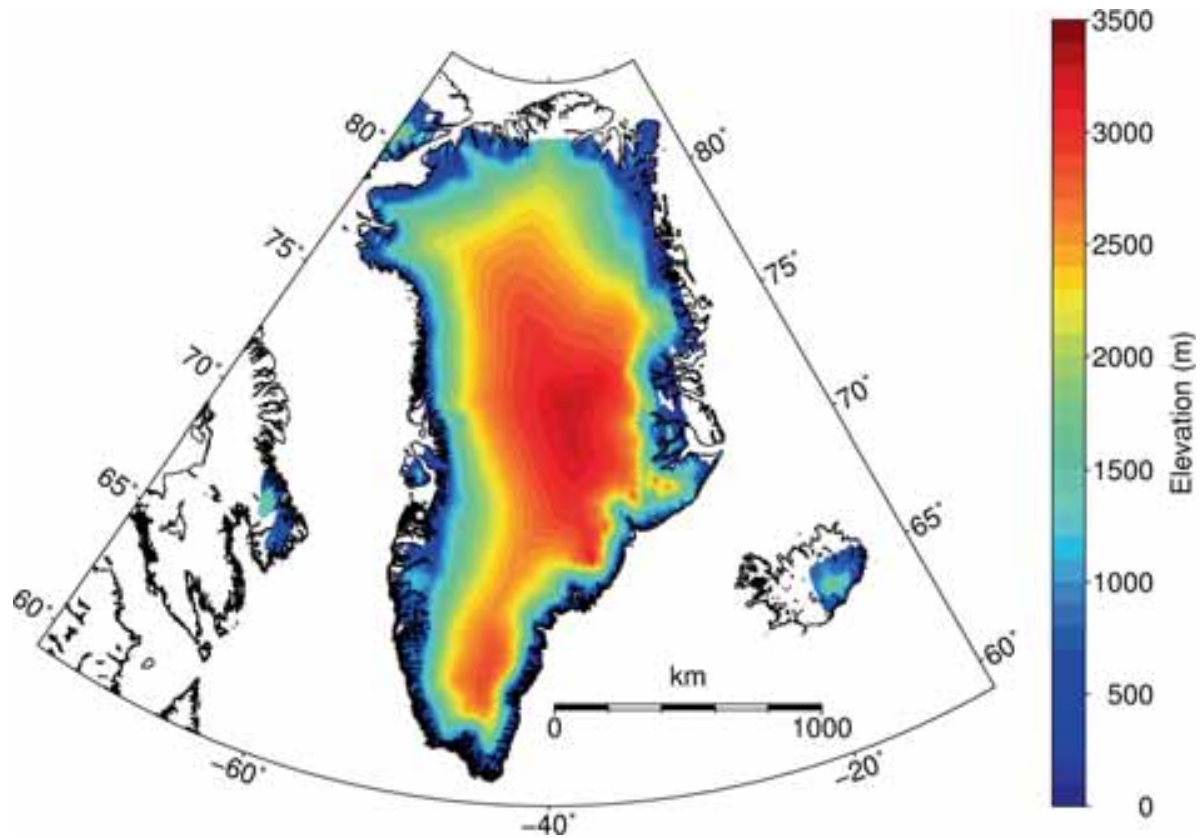

Figure 2. Slope corrected elevation map of the GrIS was derived from SARAL/AltiKa cycle 01 (14 March-18 April 2013).

The elevation map indicated maximum elevation of GrIS at $3279 \mathrm{~m}$ with average elevation value of $2048 \mathrm{~m}$. To quantify the accuracy of the slope uncorrected and corrected elevation map, we have compared the AltiKa-derived elevation with ICESat DEM-derived elevations. It was observed that although the correlation and root mean square deviation (RMSD) remained similar with values around 0.95 and $267 \mathrm{~m}$, respectively, for both slope uncorrected and corrected elevation, bias value reduced to $48.31 \mathrm{~m}$ from $64.65 \mathrm{~m}$. The large RMSD value can be attributed to the difference in period, along with interpolation methodology and undulating surface topography. As differences in slope corrected and uncorrected elevation is at a metre level and will not be visible in the case of the $\mathrm{km}$ level elevation hence only slope corrected elevation map is displayed. In spite of large RMSD values, 
we did further processing with elevations, as relative accuracy is high in comparison with absolute accuracy in the case of altimeter (highly precise instruments). Elevation change over the same surface will have a nearly similar/same error (Hurkmans et al. 2012).

Furthermore, to derive decadal elevation change, AltiKa35 elevations were corrected for penetration bias due to $\mathrm{Ka}$ band frequency. AltiKa-derived elevations (cycle 12, April-May 2014) when interpolated at ATM measured elevations of 5 April 2014, yielded bias of $0.38 \mathrm{~m}$ and 0.99 correlation for 2295 number of observation points over the GrIS region. This penetration bias is removed from the AltiKa35 elevation.

Annual elevation change results, over different regions of GrIS having different slope values were validated with ATM measurements which yielded a RMSD of $0.12 \mathrm{~m}$ for a relatively flat terrain (ROI-1) with a slope value of $0.19^{\circ}$ and $1.79 \mathrm{~m}$ for ROI- 2 with a slope value of $0.60^{\circ}$. This reveals the fact that the altimeter results are highly slope dependent, indeed RMSD increases with the increase in slope. Hence, we have limited our analysis to the region having slope values less than or equal to $1^{\circ}$ which lead to $16 \%$ data reduction over the study region.

\subsection{Impact of backscatter change on elevation change}

The impact of backscatter change on elevation change derived using cycles 11, 22 and 32 has been studied. Primarily, we have applied stringent data editing criteria $\left(-5.00 \mathrm{~dB} \leq \Delta \sigma_{0} \leq 5.00 \mathrm{~dB}\right.$, $-0.5 \mathrm{~m} \leq \Delta H \leq 0.5 \mathrm{~m}$, slope $\leq 0.1^{\circ}$ ) so that the ideal flat surface will be selected which can give maximum correlation (Davis and Ferguson 2004; Qiang et al. 2015) and measured correlation between elevation and backscatter change. This comparison yielded 0.12 (number of points $=$ 12,675 ) (figure 3) and 0.03 (number of points $=$ $12,026)$ correlation for difference of cycles 22, 11 and 32,22 , respectively.

From these results we can infer that selecting same season cycles for understanding elevation changes will not get affected by backscatter changes.

\subsection{Elevation and volume changes of the GrIS}

The difference map of AltiKa35 (March 2013-July 2016) elevation and ICESat DEM (February 2003-June 2005) elevations (figure 4) resulted in the negative volume change of $247 \mathrm{~km}^{3} /$ year over the entire GrIS. During this period, irrespective of the elevation, all basins had negative elevation and volume changes. The maximum negative elevation change ( $0.36 \mathrm{~m} /$ year $)$ was measured over basin 8.2 located in the north-west GrIS and the minimum negative elevation change $(0.06 \mathrm{~m} /$ year $)$ was over basin 7.1 located in the south-west GrIS. The coastal region of GrIS displays negative elevation change while the stable areas were located at the interior of GrIS (figure 4). The maximum negative volume change $\left(31 \mathrm{~km}^{3} /\right.$ year$)$ was measured over

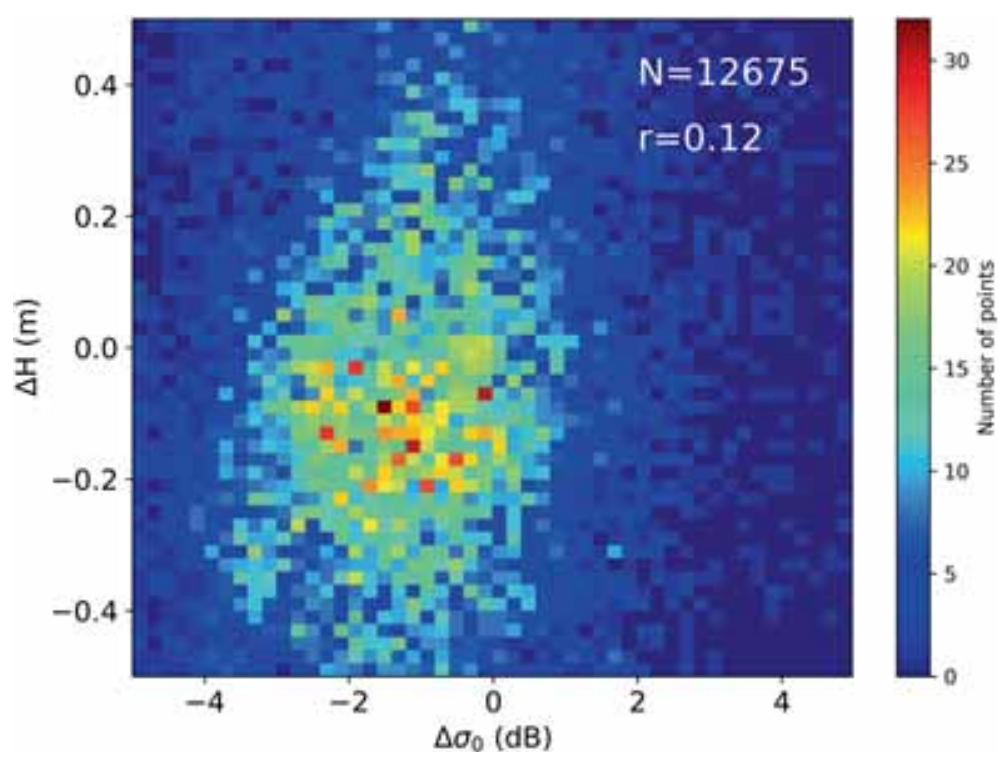

Figure 3. Density plot showing correlation between elevation change $(\Delta \mathrm{H})$ and backscatter change $\left(\Delta \sigma_{0}\right)$ between cycle 22 (Mar-Apr 2015) and cycle 11 (Feb-Apr 2014). 


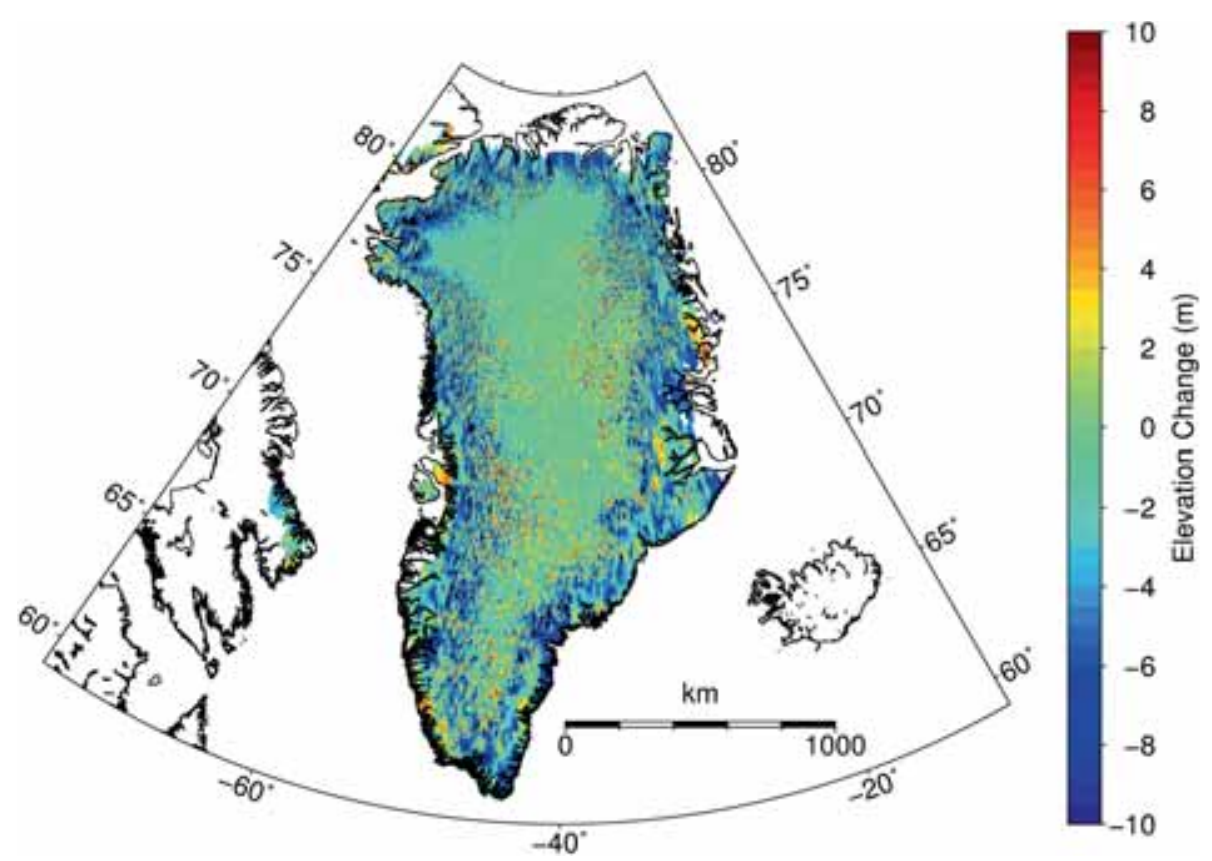

Figure 4. Elevation change map (after the removal of outlier) of GrIS for AltiKa (2013-2016)-ICESat (2003-2005).

basin 8.1 located in the north-west GrIS and the minimum negative volume change $\left(4 \mathrm{~km}^{3} /\right.$ year $)$ was measured over basin 1.4 located in the northeast GrIS. The maximum negative elevation and volume changes observed over basins 8.1 and 8.2 which were located in northwest region were in accordance with the results of Pritchard et al. (2010) who observed mass loss in the north, and the north-west region of GrIS using ICESat altimeter data for the period between 2003 and 2009. Furthermore, they attributed this mass loss to the glacier acceleration located in this area.

While deriving the annual elevation and volume change, results with cycle 01 were not discussed, as it has been observed that cycle 01 was not exactly in orbit of its past mission-Envisat and inclination manoeuvre have been applied to it (Chander et al. 2015; Remy et al. 2015). During 2014-2015 and 2015-2016 we observed a decrease in elevation and volume changes over the entire GrIS. Annual elevation changes during 2014-2015 (figure 5) indicate more than $50 \%$ of the decrease in elevation change which can be attributed to the very warm summer of July 2015, which prevailed along the north and north-western coast (nsidc.org/greenland.today/2015/11/2015-melt-season-in-review).

However, this extreme melting that occurred may be driven by the exceptional atmospheric condition characterised by new records in mean zonal winds and jet stream wave amplitude associated with the formation of arctic cut-off high
(Tedesco et al. 2016). The monotonic increase in the percentage of negative elevation change to $58 \%$ during 2015-2016 (figure 6) from 54\% of 2014-2015, confirms the 2016 summer was a warmer summer than summer 2015 (nsidc.org/Greenland.today/2016/10/2016-melt-season-in-review).

Furthermore, we took three new ROIs as selected by Li and Davis (2008), to study the recent changes occurring over these ROIs. ROI-3 $\left(68.5-69.5^{\circ} \mathrm{N}, 46-50^{\circ} \mathrm{W}\right.$, the Jakobshavan glacier) indicates the negative change $(2.07 \mathrm{~m})$ over the Jakobshavan glacier during 2014-2015 and the positive change $(0.31 \mathrm{~m})$ during $2015-2016$. During 2003-2005 to 2013-2016, ROI-3 displayed 1.39 m/ year negative elevation change. ROI-4 $\left(68-71^{\circ} \mathrm{N}\right.$, $30-36^{\circ} \mathrm{W}$, Kangerdlugssuaq) displayed $0.47 \mathrm{~m}$ positive elevation change during 2014-2015 and observed negligible negative elevation changes (0.03 m) during 2015-2016. During 2003-2005 to 2013-2016, negative elevation change with value $0.40 \mathrm{~m} /$ year was observed. ROI-5 $\left(64-67^{\circ} \mathrm{N}\right.$, $40-44^{\circ} \mathrm{W}$, southeast glacier) displayed positive elevation change $(0.90 \mathrm{~m})$ during 2014-2015 and negative elevation change $(0.14 \mathrm{~m})$ during 2015-2016. During 2003-2005 to 2013-2016, negative elevation change with a value of $0.45 \mathrm{~m} /$ year was observed. This indicates that although annual change fluctuates between the positive and negative value, a decreasing trend was continued during the decadal changes over the selected ROIs as observed by Li and Davis (2008) during 1995-2006. 


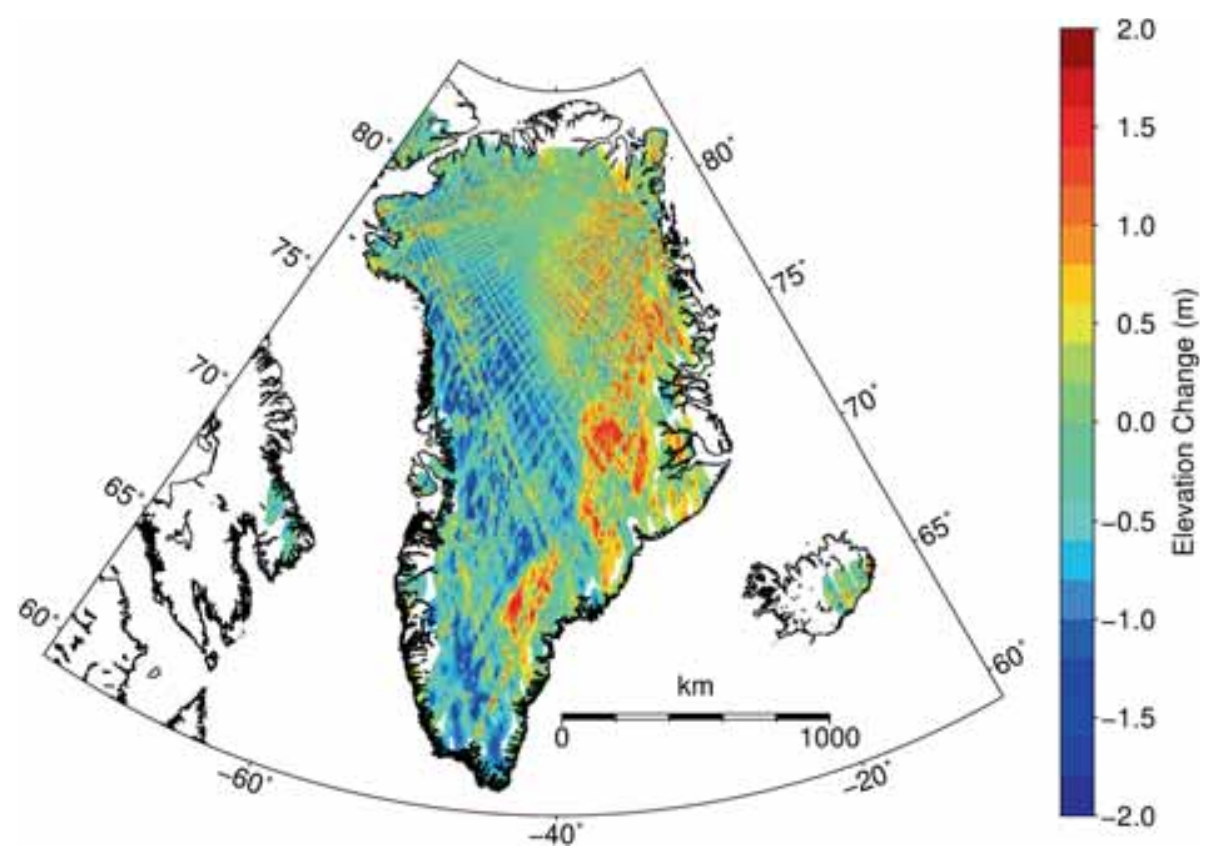

Figure 5. Elevation change map (after the removal of outlier) of GrIS for cycle 22 (Mar-Apr 2015)-cycle 11 (Feb-Apr 2014).

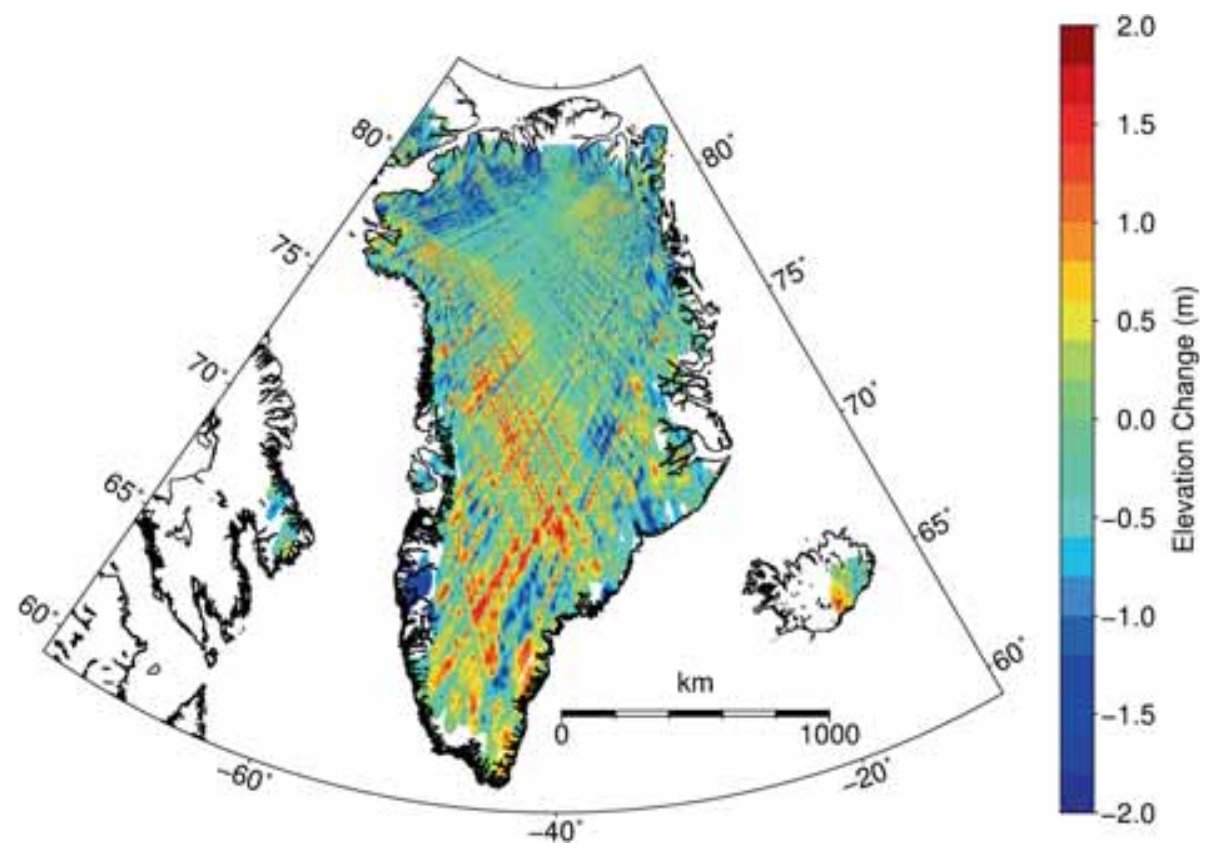

Figure 6. Elevation change map (after the removal of outlier) of GrIS for cycle 32 (Mar-Apr 2016)-cycle 22 (Mar-Apr 2015).

Moreover, annual basin-wise elevation changes (table 2) were derived. However, basins 8.1, 8.2, 1.1, 1.2 and 1.3 underwent negative elevation changes during both years 2014-2015 and 2015-2016 while positive elevation changes were measured in basin 3.3 located in the south-east. This indicates that the north and north-west region of GrIS where basins 8.1, 8.2, 1.1, 1.2 and 1.3 were located underwent a decrease in elevation change. Reported literature also indicates high thinning rates in the north and north-west region of GrIS (Abdalati et al. 2001; Pritchard et al. 2010; Wang et al. 2018). Out of these five basins, four basins were located below $2000 \mathrm{~m}$ elevation while basin 3.3 was located at the highest elevation among all basins. This suggests that individual basin elevation may be the probable reason behind the observed changes, as it has been observed that the ice sheet above $2000 \mathrm{~m}$ has been almost exactly in balance for the past few decades (Thomas et al. 
Table 2. Basin-wise inter-annual and intra-annual elevation and volume change estimates over GrIS.

\begin{tabular}{|c|c|c|c|c|c|c|c|c|}
\hline \multirow[b]{2}{*}{ Basin } & \multirow[b]{2}{*}{$\begin{array}{c}\text { Area } \times 10^{6} \\
\left(\mathrm{~km}^{2}\right)\end{array}$} & \multirow[b]{2}{*}{$\begin{array}{c}\text { Elevation } \\
(\mathrm{m})\end{array}$} & \multicolumn{2}{|c|}{ AltiKa-ICESat } & \multicolumn{2}{|c|}{ Cycle 22-cycle 11} & \multicolumn{2}{|c|}{ Cycle 32-cycle 22} \\
\hline & & & $\begin{array}{l}\text { Elevation } \\
\text { change }(\mathrm{m})\end{array}$ & $\begin{array}{c}\text { Volume } \\
\text { change } \times 10^{3} \\
\left(\mathrm{~km}^{3}\right)\end{array}$ & $\begin{array}{c}\text { Elevation } \\
\text { change }(\mathrm{m})\end{array}$ & $\begin{array}{c}\text { Volume } \\
\text { change } \times 10^{3} \\
\left(\mathrm{~km}^{3}\right)\end{array}$ & $\begin{array}{c}\text { Elevation } \\
\text { change }(\mathrm{m})\end{array}$ & $\begin{array}{c}\text { Volume } \\
\text { change } \times 10^{3} \\
\left(\mathrm{~km}^{3}\right)\end{array}$ \\
\hline 1.1 & 0.126 & 1882.807 & -2.293 & -0.288 & -0.216 & -0.027 & -0.558 & -0.070 \\
\hline 1.2 & 0.061 & 1932.392 & -1.853 & -0.113 & -0.060 & -0.004 & -0.635 & -0.039 \\
\hline 1.3 & 0.044 & 1828.559 & -1.922 & -0.085 & -0.009 & 0.000 & -0.391 & -0.017 \\
\hline 1.4 & 0.017 & 1457.614 & -3.191 & -0.053 & 0.182 & 0.003 & -0.107 & -0.002 \\
\hline 2.1 & 0.265 & 2276.417 & -0.975 & -0.258 & 0.188 & 0.050 & -0.240 & -0.064 \\
\hline 2.2 & 0.050 & 2350.990 & -1.088 & -0.054 & 0.347 & 0.017 & -0.238 & -0.012 \\
\hline 3.1 & 0.146 & 2735.779 & -1.354 & -0.198 & 0.510 & 0.074 & -0.225 & -0.033 \\
\hline 3.2 & 0.036 & 1898.838 & -2.253 & -0.081 & 0.354 & 0.013 & -0.573 & -0.020 \\
\hline 3.3 & 0.074 & 2817.283 & -1.228 & -0.091 & 0.263 & 0.019 & 0.065 & 0.005 \\
\hline 4.1 & 0.066 & 2561.009 & -1.096 & -0.072 & -0.065 & -0.004 & 0.113 & 0.007 \\
\hline 4.2 & 0.048 & 2220.534 & -2.661 & -0.128 & 0.455 & 0.022 & -0.360 & -0.017 \\
\hline 4.3 & 0.035 & 2608.027 & -2.349 & -0.082 & 0.017 & 0.001 & -0.407 & -0.014 \\
\hline 5.0 & 0.053 & 2262.384 & -2.761 & -0.146 & -0.782 & -0.041 & -0.009 & 0.000 \\
\hline 6.1 & 0.052 & 2338.403 & -1.659 & -0.087 & -0.665 & -0.035 & 0.276 & 0.014 \\
\hline 6.2 & 0.140 & 2009.926 & -1.964 & -0.275 & -0.354 & -0.049 & 0.177 & 0.025 \\
\hline 7.1 & 0.095 & 2558.784 & -0.760 & -0.073 & -0.397 & -0.038 & 0.093 & 0.009 \\
\hline 7.2 & 0.129 & 2588.220 & -1.288 & -0.166 & -0.457 & -0.059 & 0.160 & 0.021 \\
\hline 8.1 & 0.235 & 2361.490 & -1.464 & -0.344 & -0.488 & -0.115 & -0.009 & -0.002 \\
\hline 8.2 & 0.032 & 1640.376 & -4.008 & -0.129 & -0.419 & -0.014 & -0.032 & -0.001 \\
\hline
\end{tabular}

2001) and the low elevation shows widespread thinning (Abdalati et al. 2001). Thereafter, annual volume discharge by the entire GrIS during 2014-2015 and 2015-2016 was estimated to be 187 and $210 \mathrm{~km}^{3}$, respectively, indicating an enhanced decrease for the later period.

\section{Conclusions}

In the present study, we derived elevation, elevation and volume changes over GrIS using the SARAL/ AltiKa $40 \mathrm{~Hz}$ GDR dataset of the ERM phase. We observed a maximum elevation with a value $\sim 3279 \mathrm{~m}$ at the centre of the ice sheet and that continued to decrease towards the coast while average elevation was found to be $2048 \mathrm{~m}$. Annual elevation changes derived over two different regions with a slope value $0.19^{\circ}$ and $0.6^{\circ}$ were compared with the ATM dataset yielded RMSD of 0.12 and $1.27 \mathrm{~m}$, respectively. This reveals the fact that the altimeter results are highly slope-dependent, indeed RMSD increases with the increase in slope. Hence, data analysis was limited to regions having a slope value less than or equal to $1^{\circ}$.

Furthermore, the elevation difference map of AltiKa35 and ICESat DEM revealed a decreasing rate of $247 \mathrm{~km}^{3} /$ year by volume over the entire GrIS. Elevation changes obtained by differencing AltiKa cycles of the same month between two consecutive years, specifically during 2014-2015 and 2015-2016 were negative, over five basins located in the north and north-west, probably because of lower elevations, as four among them have an elevation less than $2000 \mathrm{~m}$. Positive elevation change was observed over basin 3.3 located in the south-east region is located the highest among all. During 2014-2015 and 2015-2016 the entire GrIS contributed a volume loss of 187 and $210 \mathrm{~km}^{3}$, respectively, indicating an enhanced decrease for the later period.

\section{Acknowledgements}

We express our gratitude to Shri D K Das, the Director, Space Applications Centre (SAC)-ISRO, Ahmedabad, India for encouraging us to carry out polar science studies. In addition, the encouragement and directions from Dr Rajkumar, the deputy director, EPSA-SAC-ISRO are duly acknowledged and appreciated. We also thank Dr A S Rajawat, the group director, GHCAG-EPSA-SAC-ISRO for the support offered to us during the study. 


\section{References}

Abdalati W, Krabill W, Frederick E, Manizade S, Martin C, Sonntag J, Swift R, Thomas R, Wright C and Yungel J 2001 Outlet glacier and margin elevation changes: Near coastal thinning of the Greenland ice sheet; J. Geophys. Res. 106(33) 729-733, 741.

Bamber J L 1994 Ice sheet altimeter processing scheme; Int. J. Remote Sens. 15(4) 925-938.

Bindschadler R A, Zwally H J, Major J A and Brenner A C 1989 Surface Topography of the Greenland Ice Sheet from Satellite Radar Altimetry; NASA SP:503.

Brenner A C, Bindschadler R A, Thomas R H and Zwally H J 1983 Slope-induced errors in radar altimetry over continental ice sheets; J. Geophys. Res. 88 1617-1623.

Brenner A C, Zwally H J, Cornejo H G and Saba J L 2000 Investigation of correlations between variations of radar backscatter with altimeter-derived ice sheet elevation changes and ERS-2/ERS-1 biases; In: Proceedings of the ESA ERS-Envisat symposium, Gothenburg, Sweden.

Chander S, Mishra S K, Chauhan P and Ajai 2015 Ice height and backscattering coefficient variability over Greenland ice sheets using SARAL radar altimeter; Mar. Geod. 38(Supp 1) 466-476, https://doi.org/10.1080/014490419. 2014.990590.

Davis C H and Ferguson A C 2004 Elevation change of the Antarctic ice sheet, 1995-2000, From ERS-2 Satellite Radar Altimetry; IEEE Trans. Geosci. Remote Sens. 42(11) 2437-2445.

DiMarzio J, Brenner A, Schutz R, Shuman C A and Zwally H J 2007 GLAS/ICES at $1 \mathrm{~km}$ laser altimetry digital elevation model of Greenland boulder; National Snow and Ice Data Center; Digital Media, Colorado, USA.

Helm V, Humbert A and Miller H 2014 Elevation and elevation change of Greenland and Antarctica derived from Cryosat-2; Cryosphere 8 1539-1559.

Hurkmans R T W L, Bamber J L and Griggs J A 2012 Importance of slope induced error in correction in volume change estimates from radar altimetry; Cryosphere 6 447-451, https://doi.org/10.5194/tc-6-447-2012.

Krabill W, Abdalati W, Frederick E, Manizade S, Martin C, Sonntag J, Swift R, Thomas R, Wright C and Yungel J 2000 Greenland ice sheet: High-elevation balance and peripheral thinning; Science $\mathbf{2 8 9}$ 428-430.

Krabill W, Hanna E, Huybrechts P, Abdalati W, Cappelen J, Csatho B, Frederick E, Manizade S, Martin C, Sonntag J, Swift R, Thomas R and Yungel J 2004 Greenland ice sheet: Increased coastal thinning; Geophys. Res. Lett. 31 L24402, https://doi.org/10.1029/2004GL021533.

Legresy B, Papa F, Remy F, Vinay G, Bosch van den M and Zanife O Z 2005 ENVISAT radar altimeter measurements over continental surfaces and ice caps using the ICE-2 retracking algorithm; Remote Sens. Env. 95(2) 150-163, https://doi.org/10.1016/j.rse.2004.11.018.

Li Y and Davis C 2008 Decadal mass balance of the Greenland and Antarctic ice sheet from high resolution elevation change analysis of ERS-2 and ENVISAT radar altimetry measurements; IEEE, 978-1-4244-2808-3.

Pritchard H D, Luthcke S B and Fleming A H 2010 Understanding ice-sheet mass balance: Progress in satellite altimetry and gravimetry; J. Glaciol. 56200.

Qiang Q, Zhou C, Liao M, Zhao Q and Wang Z 2015 Elevation change around dome A region of Antarctica from EnviSat satellite radar altimetry during 2002-2012; Geo-spat. Inf. Sci. 18(4) 193-199, https://doi.org/10.1080/10095020. 2015.1126072 .

Remy F, Flament T, Michel A and Verron J 2014 Ice sheet survey over Antarctica using satellite altimetry: ERS-2, Envisat, SARAL/AltiKa, the key importance of continuous observations along the same repeat orbit; Int. J. Remote Sens. 35(14) 5497-5512, https://doi.org/10.1080/014311 61.2014.926419.

Remy F, Flament T, Michel A and Blumstein D 2015 Envisat and SARAL/AltiKa observations of the Antarctic ice sheet: A comparison between the Ku-band and Ka-band; Mar. Geod. 38(S1) 510-521, https://doi.org/10.1080/01490419. 2014.985347.

Rignot E and Kanagaratnam P 2006 Changes in the velocity structure of the Greenland ice sheet; Science 311(5763) 986-990.

Suryawanshi M R, Chander S, Oza Sandip R and Bahuguna I M 2019 Variability in the ice sheet elevations over Antarctica derived from repetitive SARAL/AltiKa radar altimeter data (2013-2016); J. Earth Syst. Sci. 12864.

Tedesco M, Mote T, Fettweis X, Hanna E, Jeyaratnam J, Booth J F, Datta R and Briggs K 2016 Arctic cut-off high drives the poleward shift of a new Greenland melting record; Nat. Commun. 7 11,723, https://doi.org/10.1038/ ncomms11723.

Thomas R, Csatho B, Davis C, Kim C, Krabill W, Manizade S, McConnell J and Sonntag J 2001 Mass balance of higher elevation parts of the Greenland ice sheet; J. Geophys. Res. 106 33,707-33,716.

Van den Broeke M, Box J, Fettweis X, Hanna E, Noe B, Tedesco M, Van As D, Van de Berg W J and van Kampenhout L 2017 Greenland ice sheet surface mass loss: Recent developments in observation and modeling; Curr. Clim. Change Rep. 3 345-356, https://doi.org/10.1007/ s40641-017-0084-8.

Wang L, Liangjing Z, Chao C, Thomas M and Mikhail K K 2018 Anomalous acceleration of mass loss in the Greenland ice sheet drainage basins and its contribution to the sea level fingerprints during 2010-2012; The Cryosphere Discussion, https://doi.org/10.5194/tc-2018-142.

Yang Q, Yang Y, Wang Z, Zhang B and Jiang H 2018 Elevation change derived from SARAL/AltiKaAltimetric mission: Quality assessment and performance of the Kaband; Remote Sens. 10539.

Zwally H J, Mario B G, Mathew A B and Jack L S 2012 Antarctica and Greenland drainage systems; GSFC Cryospheric Sciences Laboratory, http://icesat4.gsfc.nasa.gov/ cryo_data/ant)grn_drainage_systems.php. 